\title{
Providencia alcalifaciens strains translocate from the gastrointestinal tract and are resistant to lytic activity of serum complement
}

\author{
Antonia B. R. Vieira, ${ }^{1,2}$ Ivan H. J. Koh ${ }^{3}$ and Beatriz E. C. Guth ${ }^{1}$ \\ ${ }^{1}$ Departamento de Microbiologia, Imunologia e Parasitologia, Universidade Federal de São Paulo - \\ Escola Paulista de Medicina, São Paulo, SP, Brazil 04023-062 \\ ${ }^{2}$ Departamento de Patologia, Universidade Federal do Pará, PA, Brazil \\ ${ }^{3}$ Disciplina de Técnica Operatória, Universidade Federal de São Paulo - Escola Paulista de Medicina, \\ São Paulo, SP, Brazil 04023-062
}

Received 11 June 2002

Accepted 7 March 2003

\begin{abstract}
The ability of Providencia alcalifaciens strains, isolated from patients with diarrhoeal disease, to translocate from the gastrointestinal tract and their resistance to serum complement lytic activity were investigated and compared with previously characterized differential invasive capabilities in HeLa cells. Translocation ability to several extraintestinal sites and resistance to lysis by human serum complement were observed in both highly invasive and non-invasive strains. These characteristics have not been previously described in $P$. alcalifaciens and their potential role in causing disseminated infections should therefore be considered.
\end{abstract}

\section{INTRODUCTION}

Providencia alcalifaciens is a member of the Enterobacteriaceae and has been implicated as an agent of diarrhoeal disease in children and adults (Haynes \& Hawkey, 1989; Albert et al., 1992; Guth et al., 1996). Recently, a large outbreak of foodborne infection was attributed to $P$. alcalifaciens, providing definitive evidence of the role of this organism in causing gastroenteritis (Murata et al., 2001).

Several studies have shown that $P$. alcalifaciens is able to invade cultured epithelial cells (Albert et al., 1992; Guth et al., 1996; Janda et al., 1998); invasion was also observed in intestinal tissues by using an adult rabbit ileal loop model (Albert et al., 1992; Mathan et al., 1993).

Previous data from our laboratory showed that invasive $P$. alcalifaciens strains, although frequently found, did not predominate among isolates from patients with diarrhoea in São Paulo, Brazil, and that non-invasive P. alcalifaciens strains were also isolated from diarrhoeal stools in pure culture from which no other bacterial enteropathogens were identified (Guth et al., 1996). However, the presence of other virulence mechanisms and the role of non-invasive $P$. alcalifaciens strains as agents of disease have not been established.

Accumulating evidence has demonstrated that bacterial translocation, defined as the passage of viable indigenous bacteria from the gastrointestinal (GI) tract to the mesenteric

Abbreviations: Gl, gastrointestinal; MLN, mesenteric lymph node. lymph node (MLN) complex and other extraintestinal sites, is an important event in the pathogenesis of opportunistic infections that originate in the human GI tract. Several bacterial species, including members of the family Enterobacteriaceae, are likely to translocate from the GI tract in animal models (Berg, 1999; Sakamoto et al., 2000). Enterobacteriaceae are also the most common cause of infection in hospitalized patients (Sedman et al., 1994; Tani et al., 1997).

Although the mechanisms responsible for bacterial translocation have not been well-elucidated, several clinical conditions, as well as the presence of virulence-associated properties (including those that allow evasion of host defences), are all predisposing factors to bacterial translocation (Sedman et al., 1994; Tani et al., 1997).

The ability of $P$. alcalifaciens to translocate from the intestinal lumen to extraintestinal sites of the host, with possible aetiology for systemic infections, has not been studied. Thus, in the present study, we evaluate the capacity for translocation and resistance to lytic activity of serum complement of invasive and non-invasive $P$. alcalifaciens strains that were previously isolated from patients with diarrhoea in our community.

\section{METHODS}

Bacterial strains. In total, 30 P. alcalifaciens strains were studied (Guth et al., 1996). Except for four strains that were isolated from asymptomatic patients, all other strains were isolated from diarrhoeal stools. Most strains were isolated in pure culture or from stool cultures in 
which no other enteropathogenic bacteria were identified. Fifteen strains were able to invade HeLa cells; the other strains did not show this characteristic. Invasion assays in HeLa cells were performed as described previously (Guth et al., 1996), except that bacterial suspension $\left(10^{9}\right.$ c.f.u. $\left.\mathrm{ml}^{-1}\right)$ was prepared and diluted $1 / 10$ in Eagle's Minimal Essential Medium (MEM; Sigma) supplemented with $10 \%$ fetal bovine serum (FBS) and $2 \% \mathrm{D}$-mannose. After $3 \mathrm{~h}$ incubation at $37^{\circ} \mathrm{C}$, the bacterial suspension was removed, the cell monolayer was washed and reincubated for $1 \mathrm{~h}$ at $37^{\circ} \mathrm{C}$ in fresh MEM-FBS that contained $150 \mu \mathrm{g}$ gentamicin $\mathrm{ml}^{-1}$.
Resistance to lytic activity of serum complement. The turbidimetric assay described by Pelkonen \& Finne (1987) was employed to test resistance of bacterial strains to serum bactericidal activity. Briefly, an overnight bacterial culture grown in Luria-Bertani (L)-broth was diluted 1/100 in fresh medium and grown until the exponential phase was reached. Bacterial cells were harvested and resuspended in L-broth to a concentration of $\sim 10^{7}$ cells $\mathrm{ml}^{-1}$ and $75 \mu \mathrm{l}$ bacterial suspension was distributed between the microplate wells. A volume of a pool of sera, prepared from blood from healthy human volunteers, was added to each well to achieve final concentrations of 36 and $50 \%$. Each strain was
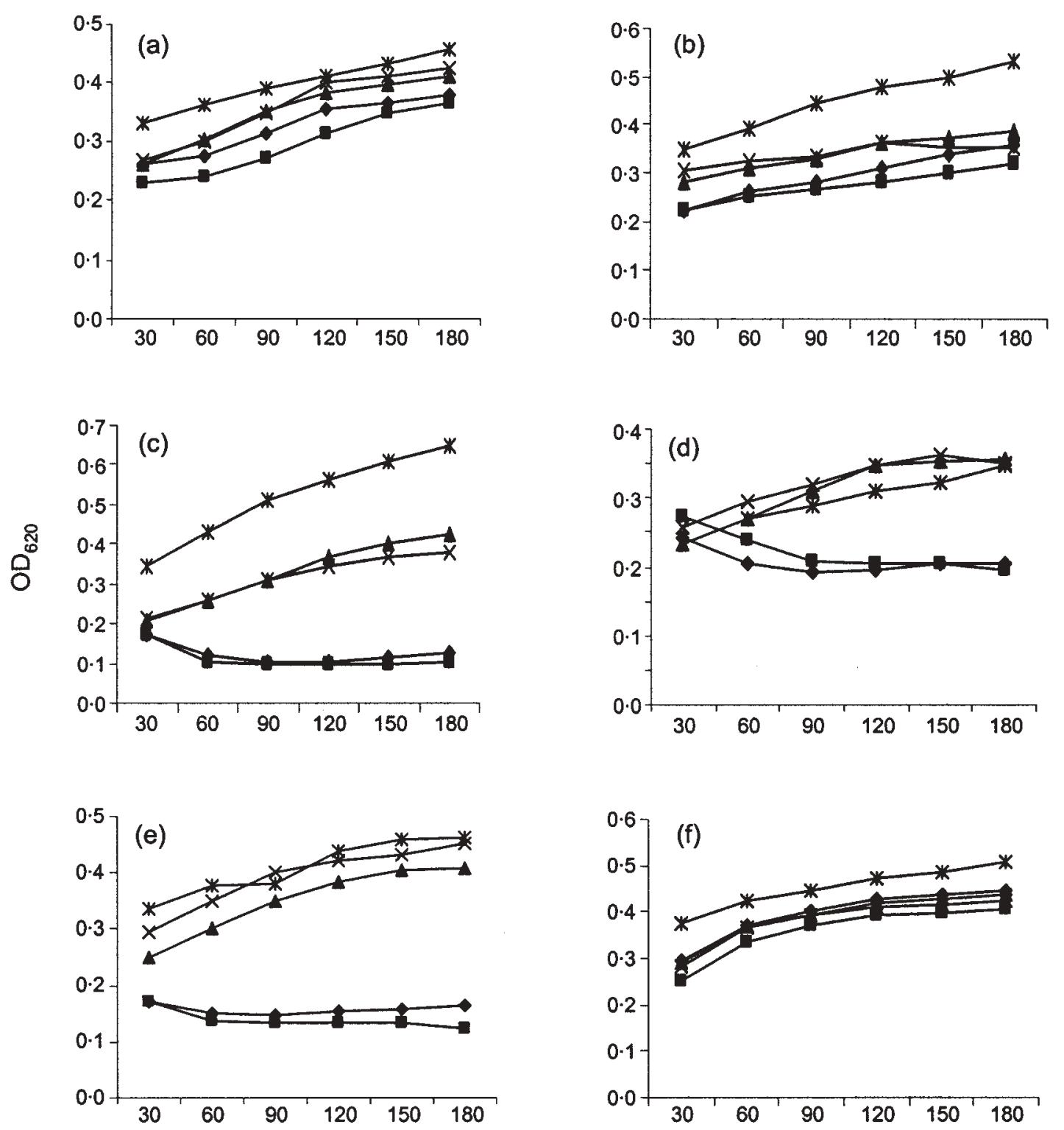

\section{Time (min)}

Fig. 1. Representative results on susceptibility to serum bactericidal activity of invasive and non-invasive $P$. alcalifaciens strains. (a) $P$. alcalifaciens 40448 (INV+); (b) P. alcalifaciens 2101-15 (INV-); (c) P. alcalifaciens 9938 (INV+); (d) P. alcalifaciens 0181-9 (INV ${ }^{-}$); (e) Escherichia coli K-12-711 (serum-sensitive); (f) Enterobacter cloacae 046 (serum-resistant). $\mathbf{\square}, 50 \%$ normal serum;, $36 \%$ normal serum; $\times, 50 \%$ inactivated serum; $\boldsymbol{\Lambda}, 36 \%$ inactivated serum; $\boldsymbol{*}$, bacterial suspension. 
tested in triplicate with both normal and heat-inactivated $\left(56{ }^{\circ} \mathrm{C}\right.$, $30 \mathrm{~min}$ ) serum. The microplates were incubated at $37^{\circ} \mathrm{C}$ and the growth ability of each strain was assessed by measurement of $\mathrm{OD}_{620}$ at 30 min intervals for $3 \mathrm{~h}$. Escherichia coli strain K-12-711 and Enterobacter cloacae strain 046 (Keller et al., 1998) were used as negative and positive controls, respectively. $P$. alcalifaciens strains were considered to be resistant to the lytic activity of serum when they were able to grow equally in normal (complement-active) and heat-inactivated (complement-inactive) serum at both 36 and $50 \%$.

Bacterial translocation. Four P. alcalifaciens strains that presented different invasive abilities and different resistance profiles to the lytic activity of serum were selected for the test. Translocation assays were performed as described by Koh \& Silva (1996); each P. alcalifaciens strain was tested six times on different days, with a total of 24 assays. Briefly, Wistar-EPM rats were fasted for 2 days and given water ad libitum. All surgical procedures were performed under aseptic conditions and the animals received ether-inhalation anaesthesia. Following oroduodenal catheterization, $10 \mathrm{ml}$ bacterial suspension in PBS, which contained $10^{10}$ c.f.u. $\mathrm{ml}^{-1}$, was inoculated into the intestinal lumen between the duodenum and ileum. MLNs, spleen, liver and blood were collected $2 \mathrm{~h}$ after inoculation. Aliquots of minced organs were cultured in MacConkey's agar at $37^{\circ} \mathrm{C}$ for $24 \mathrm{~h}$. Bacterial counts are expressed as $\log _{10}$ c.f.u. $g^{-1}$. Colonies were confirmed as inoculated bacteria by morphological characteristics and biochemical tests (Ewing, 1986). Escherichia coli strain HB 101, which is unable to translocate from the GI tract, was used as the negative control (Koh \& Silva, 1996).

\section{RESULTS AND DISCUSSION}

The role of $P$. alcalifaciens as an enteric pathogen has been observed by several authors (Haynes \& Hawkey, 1989; Guth et al., 1996; Murata et al., 2001) and as it has been reported that these bacteria can invade eukaryotic cell lines (Albert $e t$ al., 1992; Guth et al., 1996), such invasion has been proposed as a virulence mechanism. Although invasive ability seems to be strain-dependent (Guth et al., 1996; Janda et al., 1998; Sobreira et al., 2001) and, in our previous study, it was suggested to be clonally determined (Guth et al., 1999), several non-invasive $P$. alcalifaciens strains have also been isolated from patients with diarrhoea (Guth et al., 1996). However, the potential pathogenic role of these strains has not been described.
Resistance to human serum and bacterial translocation from the GI tract have been considered to be important virulence characteristics for several species, including members of the family Enterobacteriaceae (Taylor, 1983; Sedman et al., 1994; Sakamoto et al., 2000). In the present study, we report for the first time that invasive and non-invasive $P$. alcalifaciens strains demonstrated resistance to human serum bactericidal activity and the ability to translocate from the GI tract.

Resistance to lytic activity of serum complement was observed in nine of $30(30 \%)$ P. alcalifaciens strains studied; these included five invasive and four non-invasive strains. Complement-resistant invasive and non-invasive P. alcalifaciens strains were able to survive and multiply in 36 and $50 \%$ human serum, showing a growth rate $8-20 \%$ higher than the initial inoculum (Fig. 1). All other P. alcalifaciens strains were susceptible to serum bactericidal activity.

By using a small-animal model to study bacterial translocation, we observed that $P$. alcalifaciens strains demonstrated the ability to translocate from the intestinal lumen to extraintestinal sites: they were detected in MLNs, liver and spleen (Table 1). Moreover, the results showed that invasion of eukaryotic cells and resistance to human serum bactericidal activity do not appear to be determining factors in the occurrence of $P$. alcalifaciens translocation.

Although a strong correlation between serum resistance and the ability of a variety of Gram-negative bacteria to invade and survive in the human bloodstream has been demonstrated in several studies (Roantree \& Rantz, 1960; Taylor, 1983; Keller et al., 1998), the survival of apparently serumsusceptible bacteria in the blood of bacteraemic patients has also been reported; this may be related to serum ineffectiveness at killing the infectious agent or bacterial circumvention of the serum bactericidal system by adoption of an intracellular location in the blood or reticuloendothelial system (Roantree \& Rantz, 1960; Taylor, 1983).

Providencia spp. have been implicated as agents of bacteraemia and other extraintestinal infections (Cornaglia et al., 1995; Pinto et al., 1999), although P. alcalifaciens strains have

Table 1. Translocation of $P$. alcalifaciens to extraintestinal sites, invasion of HeLa cells and susceptibility to serum bactericidal activity

\begin{tabular}{|c|c|c|c|c|c|c|}
\hline \multirow[t]{2}{*}{ Strain } & \multirow{2}{*}{$\begin{array}{l}\text { Invasion of } \\
\text { HeLa cells }\end{array}$} & \multirow{2}{*}{$\begin{array}{l}\text { Susceptibility } \\
\text { to serum } \\
\text { bactericidal } \\
\text { activity } \dagger\end{array}$} & \multicolumn{4}{|c|}{ Bacterial count (c.f.u. g ${ }^{-1}$ ) } \\
\hline & & & $\begin{array}{c}\text { MLN } \\
(n=6)\end{array}$ & $\begin{array}{l}\text { Spleen } \\
(n=2)\end{array}$ & $\begin{array}{c}\text { Liver } \\
(n=2)\end{array}$ & $\begin{array}{c}\text { Blood } \\
(n=2)\end{array}$ \\
\hline 40448 & + & $\mathrm{R}$ & $8 \times 10^{4}$ & $9 \times 10^{3}$ & $8 \times 10^{3}$ & 0 \\
\hline 9938 & + & S & $2 \cdot 8 \times 10^{4}$ & $3 \times 10^{3}$ & $8.9 \times 10^{3}$ & 0 \\
\hline $0181-9$ & - & $S$ & $4 \cdot 8 \times 10^{4}$ & $2 \times 10^{3}$ & $1.8 \times 10^{3}$ & 0 \\
\hline 2101-15 & - & $\mathrm{R}$ & $2.2 \times 10^{4}$ & $4.6 \times 10^{3}$ & $1 \cdot 1 \times 10^{3}$ & 0 \\
\hline
\end{tabular}

${ }^{*}+$, Invasive; - , non-invasive.

$\dagger \mathrm{R}$, Resistant; S, susceptible. 
been related mainly to diarrhoeal diseases (Guth et al., 1996; Janda et al., 1998; Murata et al., 2001). Despite this knowledge, $P$. alcalifaciens is not recognized as a potential pathogen in most clinical laboratories and can therefore pass easily through routine screening, although a selective medium for P. alcalifaciens has been reported (Senior, 1997). The results obtained in the present study reinforce the importance of $P$. alcalifaciens as a pathogen by showing that some strains were able to translocate from the GI tract and survive the killing action of complement, giving support to the suggestion that these bacteria may have the potential to cause more disseminated infection.

\section{ACKNOWLEDGEMENTS}

This work was supported by Financiadora de Estudos e Projetos/ Ministério da Ciência e Tecnologia/Programa de Apoio a Núcleos de Excelência (FINEP/MCT/PRONEX). A.B.R.V. received a research fellowship from Coordenadoria de Aperfeiçoamento de Pessoal de Nível Superior (CAPES-PICDT).

\section{REFERENCES}

Albert, M. J., Alam, K., Ansaruzzaman, M. \& 7 other authors (1992). Pathogenesis of Providencia alcalifaciens-induced diarrhea. Infect Immun 60, 5017-5024.

Berg, R. D. (1999). Bacterial translocation from the gastrointestinal tract. In Mechanisms in the Pathogenesis of Enteric Diseases, vol. 2, pp. 11-30. Edited by P. S. Paul \& D. H. Francis. New York: Plenum.

Cornaglia, G., Frugoni, S., Mazzariol, A., Piacentini, E., Berlusconi, A. \& Fontana, R. (1995). Activities of oral antibiotics on Providencia strains isolated from institutionalized elderly patients with urinary tract infections. Antimicrob Agents Chemother 39, 2819-2821.

Ewing, W. H. (1986). Edwards and Ewing's Identification of Enterobacteriaceae, 4 th edn. New York: Elsevier.

Guth, B. E. C. \& Perrella, E. (1996). Prevalence of invasive ability and other virulence-associated characteristics in Providencia alcalifaciens strains isolated in São Paulo, Brazil. J Med Microbiol 45, 459-462.

Guth, B. E. C, Irino, K. \& Trabulsi, L. R. (1999). Clonal structure of Providencia alcalifaciens strains isolated from diarrhoeal stools in São Paulo, Brazil. J Med Microbiol 48, 205-209.

Haynes, J. \& Hawkey, P. M. (1989). Providencia alcalifaciens and travellers' diarrhoea. BMJ 299, 94-95.

Janda, J. M., Abbott, S. L., Woodward, D. \& Khashe, S. (1998). Invasion of HEp-2 and other eukaryotic cell lines by Providenciae: further evidence supporting the role of Providencia alcalifaciens in bacterial gastroenteritis. Curr Microbiol 37, 159-165.

Keller, R., Pedroso, M. Z., Ritchmann, R. \& Silva, R. M. (1998). Occurrence of virulence-associated properties in Enterobacter cloacae. Infect Immun 66, 645-649.

Koh, I. H. J. \& Silva, R. M. (1996). Novel in vitro small intestinal graft model for study of bacterial translocation in the rat. Transplant Proc 28, $2667-2668$.

Mathan, M. M., Mathan, V. I. \& Albert, M. J. (1993). Electron microscopic study of the attachment and penetration of rabbit intestinal epithelium by Providencia alcalifaciens. J Pathol 171, 67-71.

Murata, T., lida, T., Shiomi, Y., Tagomori, K., Akeda, Y., Yanagihara, I., Mushiake, S., Ishiguro, F. \& Honda, T. (2001). A large outbreak of foodborne infection attributed to Providencia alcalifaciens. J Infect Dis 184, 1050-1055.

Pelkonen, S. \& Finne, J. (1987). A rapid turbidimetric assay for the study of serum sensitivity of Escherichia coli. FEMS Microbiol Lett 42, 53-57.

Pinto, V., Telenti, M., Bernaldo de Quiros, J. F. \& Palomo, C. (1999). Two cases of fatal transfusion-associated bacterial sepsis provoked by Providencia rettgeri. Haematologica 84, 1051-1052.

Roantree, R. J. \& Rantz, L. A. (1960). A study of the relationship of the normal bactericidal activity of human serum to bacterial infection. J Clin Invest 39, 72-81.

Sakamoto, K., Hirose, H., Ezaki, T., Kawamura, Y., Onizuka, A., Hayashi, M., Yamada, T. \& Sago, T. (2000). Translocation of Salmonella typhimurium in rats; effect of enteral and parenteral nutrition. Eur J Surg 166, 814-817.

Sedman, P. C., Macfie, J., Sagar, P., Mitchell, C. J., May, J., ManceyJones, B. \& Johnstone D. (1994). The prevalence of gut translocation in humans. Gastroenterology 107, 643-649.

Senior, B. W. (1997). Media for the detection and recognition of the enteropathogen Providencia alcalifaciens in faeces. J Med Microbiol 46, 524-527.

Sobreira, M., Leal, N. C., Magalhães, M., Guth, B. E. C. \& Almeida, A. M. P. (2001). Molecular analysis of clinical isolates of Providencia alcalifaciens. J Med Microbiol 50, 29-34.

Tani, T., Hanasawa, K., Endo, Y., Kurumi, Y., Shiomi, H., Kodama, M., Kushima, R. \& Hattori, T. (1997). Bacterial translocation as a cause of shock in humans: a report of two cases. Surg Today 27, 447-449.

Taylor, P. W. (1983). Bactericidal and bacteriolytic activity of serum against Gram-negative bacteria. Microbiol Rev 47, 46-83. 